\title{
Predictors of mortality in chronic pulmonary aspergillosis
}

\author{
David Lowes ${ }^{1,3}$, Khaled Al-Shair ${ }^{1,3}$, Pippa J. Newton ${ }^{1}$, Julie Morris ${ }^{2}$, \\ Chris Harris ${ }^{1}$, Riina Rautemaa-Richardson ${ }^{1}$ and David W. Denning ${ }^{1,2}$
}

Affiliations: ${ }^{1}$ The National Aspergillosis Centre, University Hospital of South Manchester, The University of Manchester, Manchester Academic Health Science Centre, Manchester, UK. ${ }^{2}$ Dept of Medical Statistics, University Hospital of South Manchester, The University of Manchester, Manchester Academic Health Science Centre, Manchester, UK. ${ }^{3}$ Both authors contributed equally.

Correspondence: David Denning, The National Aspergillosis Centre, University Hospital of South Manchester, Southmoor Road, Manchester, M23 9LT, UK. E-mail: ddenningamanchester.ac.uk

@ERSpublications

This article describes the world's largest experience of chronic pulmonary aspergillosis and its outcome http://ow.ly/pG9X305Yw8L

Cite this article as: Lowes D, Al-Shair K, Newton PJ, et al. Predictors of mortality in chronic pulmonary aspergillosis. Eur Respir J 2017; 49: 1601062 [https://doi.org/10.1183/13993003.01062-2016].

ABSTRACT Chronic pulmonary aspergillosis (CPA) is a chronic progressive infection that destroys lung tissue in non-immunocompromised patients. Contemporary series suggest $50-85 \%$-year mortality, with few prognostic factors identified.

A cohort of 387 CPA patients referred to the UK's National Aspergillosis Centre from 1992 to June 2012 was studied until June 2015. The impact of objective and subjective variables including age, sex, previous pulmonary conditions, dyspnoea score, quality of life, serum albumin and C-reactive protein and radiological appearances were assessed using Kaplan-Meier curves, log rank tests and Cox proportional hazards modelling. In samples of patients, retrospective review of time from likely onset of CPA to referral and cause of death were also investigated.

Survival was $86 \%, 62 \%$ and $47 \%$ at 1,5 and 10 years, respectively. Increased mortality was associated with nontuberculous mycobacterial infection (hazard ratio 2.07, 95\% CI 1.22-3.52; p<0.001) and chronic obstructive pulmonary disease $(1.57,1.05-2.36 ; \mathrm{p}=0.029)$ as well as higher age $(1.053,1.03-1.07$ per year; $\mathrm{p}<0.001)$, lower albumin $\left(0.92,0.87-0.96\right.$ per $\left.\mathrm{g} \cdot \mathrm{L}^{-1}\right)$, lower activity $(1.021,1.01-1.03$ per point increase in St George's Respiratory Questionnaire activity domain; $\mathrm{p}<0.001)$ and having one, and especially, bilateral aspergillomas $(\mathrm{p}<0.001)$.

Several factors impact on mortality of CPA, and can be evaluated as tools to assess CPA prognosis.

This article has supplementary material available from erj.ersjournals.com

Earn CME accreditation by answering questions about this article. You will find these at erj.ersjournals.com/journal/cme

Received: May 262016 | Accepted after revision: Oct 272016

Conflict of interest: Disclosures can be alongside this article at erj.ersjournals.com

Copyright OERS 2017 


\section{Introduction}

Chronic pulmonary aspergillosis (CPA) is an infectious disease that often progressively destroys lung tissue. It occurs principally in immunocompetent individuals with a previous or underlying pulmonary condition such as tuberculosis or chronic obstructive pulmonary disease (COPD) [1]. Awareness of this debilitating and ultimately fatal infection is increasing, and it is provisionally estimated that there are 3 million patients with CPA worldwide [2].

There are three major patterns of disease: simple aspergilloma, chronic cavitary pulmonary aspergillosis (CCPA) and Aspergillus nodule [3]. Simple aspergilloma is defined as a single pulmonary cavity containing a fungal ball, and is often cured by surgical resection [4-6]. CCPA is characterised by cavity formation and progression without overt tissue invasion and is associated with significant morbidity and mortality in contrast to simple aspergilloma. However, other aspects of the impact of CPA, such as pleural involvement and bilateral aspergilloma on mortality risk needs further investigation.

CPA is usually diagnosed by a combination of symptoms, characteristic radiological appearances in a non-immunocompromised individual and detectable Aspergillus IgG antibodies [7, 8]. Patients present initially with nonspecific symptoms including chronic cough, shortness of breath, weight loss and haemoptysis [3]. Progression over months or years results in significant loss of functional capacity and decline in quality of life [9]. Functional capacity reduction and quality of life impairment reliably predict mortality risk in chronic respiratory illnesses such as COPD [10, 11]. However, these key measures of health status have not been investigated in CPA with respect to prognosis.

We found only nine studies with sample sizes of 11-194 subjects reporting divergent data on the survival of CPA patients, with 5-year survival ranging from $17.5 \%$ to $85 \%$ [12-20], as summarised in table 1 .

Using data from a cohort of 392 CPA patients, we present data on long-term survival from an experienced single centre with a consistent approach to antifungal therapy. In addition, using a wide range of objective and subjective measures, we examine factors associated with mortality risk in CPA.

\section{Patients and methods}

\section{Study design}

This retrospective study reviewed patients referred to the National Aspergillosis Centre (NAC; Manchester, UK) for medical management of CPA from June 1, 1992 until June 1, 2012. 18 patients were seen prior to 2000 [3]. Survival data were collected in June 2015, resulting in a minimum follow-up of 3 years for surviving patients. The clinical records of all patients were examined and the diagnosis of CPA confirmed using criteria modified from DenNing et al. [3], and described in detail by FARID et al. [5] and consistent with the recently published European guideline on CPA [21]. Radiological and immunological examinations were used to identify immunocompetent patients with a history of cavitary or nodular disease caused by Aspergillus of $\geqslant 3$ months' duration [5, 22]. Further information on the inclusion and exclusion criteria is provided in the online supplementary material, together with the STROBE (Strengthening the Reporting of Observational Studies in Epidemiology) criteria checklist and a figure showing the disposition of patients (online supplementary figure S1).

The variables collected on these patients included sex, age at referral, previous or current underlying pulmonary conditions, St George's Respiratory Questionnaire (SGRQ) score, serum albumin and C-reactive protein (CRP), sputum culture positivity for Aspergillus species and antifungal susceptibility and radiological appearances. The computed tomography (CT) scan closest to referral was reviewed (usually obtained prior to referral). The CT scan appearances were categorised by unilateral or bilateral disease, presence of pleural involvement (thickening) or not, cavitary or nodular appearances and presence and location of aspergillomas. The full medical records of a random sample of 120 patients were manually reviewed to record the baseline Medical Research Council (MRC) dyspnoea score (initiated in late 2009) ( $\mathrm{n}=78)$, baseline weight $(\mathrm{n}=102)$ and body mass index (BMI) $(n=88)$, all antifungal treatment administered $(n=108)$ and to determine the date of the probable onset of CPA. Baseline was defined as within 6 months of referral for all variables, with the exception of MRC dyspnoea score (within 12 months of referral). Causes of death were available for 40 patients.

The MRC dyspnoea scale is a well-validated tool $[23,24]$ that has been widely used in the respiratory field, including for CPA [9]. Quality of life was assessed using the 76-item SGRQ, which consists of three domains (symptoms, activity and impact), and total score [25]. The scores range from 0 to 100, and a higher score indicates worse quality of life $[25,26]$. Our work has extensively examined its validity and reliability [27] and sensitivity to change with treatment in CPA [9].

\section{Therapeutic approach}

At the NAC, patients were treated with oral triazole therapy where possible. First-line therapy was usually itraconazole, which was switched to voriconazole (from 1993) [28] or posaconazole solution (from 2007) [7] 
TABLE 1 Studies reporting survival of patients with chronic pulmonary aspergillosis (CPA)

\begin{tabular}{|c|c|c|c|c|c|c|c|c|}
\hline \multirow[t]{2}{*}{ Authors [ref.] } & \multirow[t]{2}{*}{ Year } & \multirow[t]{2}{*}{ Country } & \multirow[t]{2}{*}{ Subjects n } & \multirow[t]{2}{*}{ Subcategory } & \multicolumn{3}{|c|}{ Survival \% } & \multirow{2}{*}{$\begin{array}{c}\text { Duration of } \\
\text { observation period }\end{array}$} \\
\hline & & & & & 1 year & 5 years & 10 years & \\
\hline \multirow[t]{2}{*}{ JEWKES et al. [12] } & \multirow[t]{2}{*}{1983} & \multirow[t]{2}{*}{ UK } & 40 & $\begin{array}{c}\text { Surgical } \\
\text { management }\end{array}$ & 90 & 85 & 50 & \multirow{3}{*}{$\begin{array}{l}\text { The mean follow-up period } \\
\text { was } 8.7 \text { years and } 85 \% \text { of } \\
\text { patients were followed for } \\
5 \text { years or until death } \\
\text { Review of medical notes } \\
\text { from } 1975 \text { to } 1985 \text {. } \\
\text { Follow-up period ranged } \\
\text { from } 2 \text { to } 11 \text { years where the } \\
\text { majority were followed for } \\
>4 \text { years from the } \\
\text { aspergilloma diagnosis }\end{array}$} \\
\hline & & & 36 & $\begin{array}{l}\text { Conservative } \\
\text { management }\end{array}$ & 90 & 57.5 & 37.5 & \\
\hline ToMLINSON and & 1987 & USA & 12 & Prior TB & 80 & 60 & $<40$ & \\
\hline NAM et al. [14] & 2010 & $\begin{array}{l}\text { South } \\
\text { Korea }\end{array}$ & 43 & Prior TB/NTM 93\% & 65 & 50 & 30 & $\begin{array}{c}\text { Medical records for patients } \\
\text { between } 1995 \text { and } 2007 \\
\text { were reviewed } \\
\text { The median follow-up period } \\
\text { from disease diagnosis to } \\
\text { either death or closing date } \\
\text { was } 15 \text { months (IQR 2.5- } \\
32 \text { months) for all patients }\end{array}$ \\
\hline Онва et al. [15] & 2012 & Japan & 42 & $\begin{array}{c}\text { Prior TB 50\%, COPD } \\
14 \%, \text { NTM } 36 \%\end{array}$ & 70 & 17.5 & & $\begin{array}{c}\text { Medical record for patients } \\
\text { between } 2001 \text { and } 2009 \text { were } \\
\text { reviewed } \\
\text { The observation period was } \\
28.7 \pm 26.6 \text { months }\end{array}$ \\
\hline JHun et al. [16] & 2013 & $\begin{array}{l}\text { South } \\
\text { Korea }\end{array}$ & 70 & $\begin{array}{l}\text { Prior TB } 81 \%, \text { COPD } \\
50 \%, \text { NTM } 46 \%\end{array}$ & 93 & & $86^{\#}$ & $\begin{array}{l}\text { Medical records of patients } \\
\text { between January } 2008 \text { and } \\
\text { January } 2011 \text { were reviewed }\end{array}$ \\
\hline Nакамото et al. [17] & 2013 & Japan & 194 & $\begin{array}{l}\text { Prior TB } 30 \% \text {, } \\
\text { emphysema } 20 \% \text {, } \\
\text { ILD } 17 \% \text {, NTM } 15 \% \text {, } \\
\text { others } 18 \%\end{array}$ & & 48.2 & 32.6 & $\begin{array}{c}\text { Medical records of patients } \\
\text { between } 1997 \text { and } 2011 \text { were } \\
\text { reviewed } \\
\text { Patients were followed-up } \\
\text { over a median } 2.6 \text { years }\end{array}$ \\
\hline TAKEDA et al. [19] & 2016 & Japan & $\begin{array}{l}41 \text { (28 with } \\
\text { CCPA) }\end{array}$ & $\begin{array}{l}\text { CPA with other } \\
\text { underlying diseases } \\
\text { but not NTM }(n=32) \\
\text { and with NTM }(n=9)\end{array}$ & 83 & $\begin{array}{c}56 \text { at } \\
3 \text { years }\end{array}$ & & $\begin{array}{l}\text { Medical records of patients } \\
\text { between } 2008 \text { and } 2013 \text { were } \\
\text { reviewed; many of the } \\
\text { patients were followed-up } \\
\text { for up to } 6 \text { years from } \\
\text { diagnosis date }\end{array}$ \\
\hline ChAN et al. [20] & 2016 & $\begin{array}{l}\text { Hong } \\
\text { Kong }\end{array}$ & $\begin{array}{l}29 \mathrm{CPA} \\
31 \mathrm{PA}\end{array}$ & $\begin{array}{l}\text { Prior TB in } 69 \\
\text { and } 81 \% ; \text { COPD in } \\
41 \% \text { and } 32 \% \\
\text { (CPA and PA) }\end{array}$ & $\begin{array}{l}\text { 2-year } \\
72.4 \text { a } \\
\text { ICPA } \\
\text { respe }\end{array}$ & $\begin{array}{l}\text { survival } \\
\text { nd } 77.4 \\
\text { and PA, } \\
\text { tively })^{\pi}\end{array}$ & & $\begin{array}{l}\text { Higher leukocyte count at } \\
\text { admission was poor } \\
\text { prognostic feature of CPA } \\
\text { (multivariate) }\end{array}$ \\
\hline Lowes et al. & 2016 & UK & 387 & $\begin{array}{l}\text { Prior TB } 21 \%, \text { COPD } \\
40 \%, \text { NTM } 10 \%\end{array}$ & 86 & 62 & 47 & $\begin{array}{l}\text { Patients were followed-up } \\
\text { from } 1992 \text { to June } 2012 \text { la } \\
\text { minimum follow-up of } \\
3 \text { years for surviving } \\
\text { patients) }\end{array}$ \\
\hline
\end{tabular}

TB: tuberculosis; NTM: nontuberculous mycobacteria; IQR: interquartile range; COPD: chronic obstructive pulmonary disease; ILD: interstitial lung disease; CCPA: chronic cavitary pulmonary aspergillosis; PA: simple aspergilloma. ${ }^{\#}$ : imprecise follow-up period; ${ }^{\uparrow}$ : $p=0.77$.

in the event of intolerance, triazole resistance or clinical failure. Therapeutic monitoring and dose adjustment of triazole plasma concentrations was routine and frequent. In those unable to take oral therapy, or with pan-azole resistance, intravenous liposomal amphotericin B (AmBisome, $3 \mathrm{mg} \cdot \mathrm{kg}^{-1} \cdot \mathrm{day}^{-1}$ ) or micafungin 
(150 mg.day ${ }^{-1}$ ) were used, usually for $2-4$ weeks, but occasionally for months as outpatients with homecare support. Surgical resection was undertaken in a small proportion of patients for multiple reasons, as described previously [5].

A detailed description of consent and statistical analysis is provided in the online supplementary material.

\section{Results}

392 patients fulfilling criteria for CPA were referred to the NAC during the study period; 50\% of the total referrals with aspergillosis. Five patients were lost to follow-up, so 387 patients were studied. Of these, $>95 \%$ were caucasian (96.4\%), 219 (56.6\%) patients were male, the mean \pm SD age at referral was $59.4 \pm 13.0$ years (range 18-86 years) and 166 patients had died over the study period. The mean follow-up of surviving patients was 5.65 years; the time from referral to death in nonsurviving patients $(n=166)$ was 2.85 years. Figure 1 shows a survival curve from time of referral to the NAC. Overall, the 1-, 5- and 10-year survival rates in our 387 patients were $86 \%, 62 \%$ and $47 \%$, respectively (table 1 ). The hazard ratio (HR) for death for every 10 -year increase in age at referral was $1.69(\mathrm{p}<0.001)$. Sex of the patient had no impact on survival $(\log \operatorname{rank} \mathrm{p}=0.067)$. There was no time trend for the first and second $50 \%$ of patients referred (online supplementary figure S4).

Oral antifungal therapy had been initiated in $98 \%$ of 108 patients analysed in detail. Itraconazole was used as first-line therapy in $77 \%$ of patients, voriconazole in $15.2 \%$ and posaconazole in $7.6 \%$. At least 1 month of oral itraconazole, voriconazole and posaconazole was administered to $73.1 \%, 57.4 \%$ and $23.1 \%$ of patients, respectively; $8.3 \%$ of patients did not receive $\geqslant 1$ month of oral therapy. Of patients who were initiated on itraconazole, $65 \%$ were switched to voriconazole, and $21 \%$ of these were later escalated to posaconazole. Of those starting on voriconazole, $12.5 \%$ were switched to posaconazole. More than $81 \%$ of patients attending the NAC for more than a year had received $\geqslant 1$ year of oral therapy. Of those who did not have 1 year of therapy, $47 \%$ had received at least one course of i.v. voriconazole, liposomal amphotericin B or micafungin. 16 patients had surgical resection of CPA-unresponsive lesions or for haemoptysis, and of these six (37.5\%) relapsed, as reported previously [5].

Accurate data on underlying disease were available for 362 patients. The median (interquartile range, range) number of underlying pulmonary conditions was $2(1-3,0-6)$. As shown in table 2, COPD was the most common underlying disease $(n=145)$, followed by pneumonia and tuberculosis $(n=79$ and $n=76$, respectively). Several co-existing pulmonary illnesses were associated with increased mortality risk in CPA; however, multivariable Cox regression analysis (including all underlying conditions and age) showed that nontuberculous mycobacterial (NTM) disease infection (HR 2.212, p<0.001) and COPD (HR 1.580, $\mathrm{p}=0.006$ ) were associated with worse survival (table 2).

Baseline SGRQ data were available for 327 patients. The activity domain was the only significant predictor of survival by multivariate model including all domains; an increase of 4 points had a HR of 1.13 (95\% CI $1.09-1.18 ; \mathrm{p}<0.001)$.

Baseline serum albumin (online supplementary figure S1) and CRP data were available for 351 patients. Higher CRP was predictive of mortality in a univariate model (HR 1.03, 95\% CI 1.01-1.04; p<0.001 for a $5 \mathrm{mg} \cdot \mathrm{L}^{-1}$ increase in CRP), but this significance was lost in a multivariate analysis with albumin, which was related to an $11 \%$ decrease in mortality risk per $1 \mathrm{~g} \cdot \mathrm{L}^{-1}$ increase (HR 0.89, 95\% CI 0.86-0.92; $\mathrm{p}<0.001)$.

FIGURE 1 Censored survival curve of patients from the first visit to the National Aspergillosis Centre. $\mathrm{n}=387.1-, 5$ - and 10-year survival $86 \%, 62 \%$ and $47 \%$, respectively.

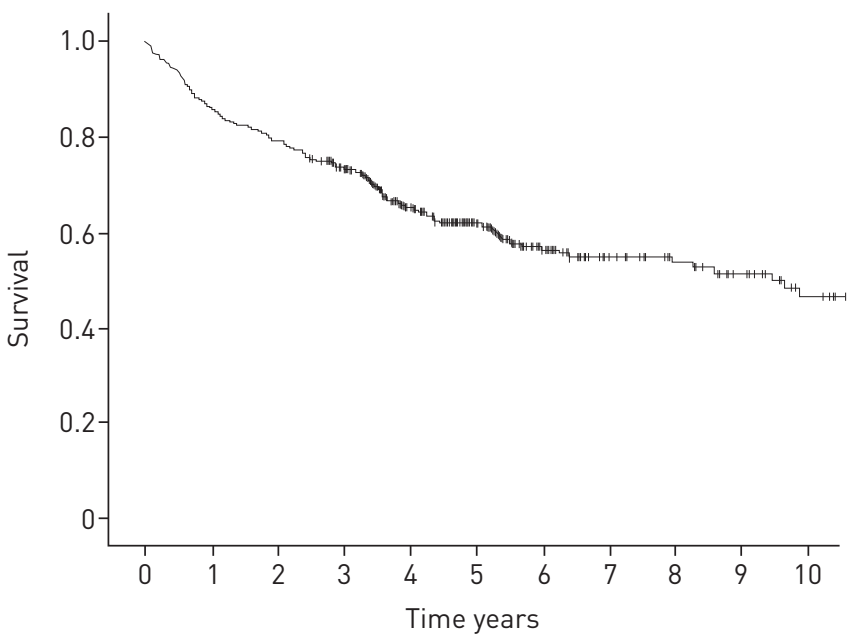


TABLE 2 Underlying pulmonary diseases and their effect on survival of 387 chronic pulmonary aspergillosis patients, not including those with simple aspergilloma

\begin{tabular}{|c|c|c|c|c|c|c|}
\hline & \multirow[t]{2}{*}{ Patients } & \multicolumn{3}{|c|}{ Kaplan-Meier analysis } & \multicolumn{2}{|c|}{$\begin{array}{l}\text { Cox proportional hazards model including } \\
\text { all underlying conditions and age }\end{array}$} \\
\hline & & 2-yea & urvival & Log rank test $p$-value & Adjusted hazard ratio $(95 \% \mathrm{CI})$ & p-value \\
\hline TB & & Without & $78.3 \pm 2.5$ & & & \\
\hline \multirow[t]{2}{*}{ NTM } & $37(10.2)$ & With & $62.2 \pm 8.0$ & $<0.001$ & $2.212(1.43-3.42)$ & $<0.001$ \\
\hline & & Without & $80.9 \pm 2.2$ & & & \\
\hline \multirow[t]{2}{*}{ Asthma } & $73(20.2)$ & With & $91.8 \pm 3.2$ & 0.014 & NS & \\
\hline & & Without & $75.8 \pm 2.5$ & & & \\
\hline \multirow[t]{2}{*}{ ABPA } & $44(12.2)$ & With & $95.5 \pm 3.1$ & 0.053 & NS & \\
\hline & & Without & $76.7 \pm 2.4$ & & & \\
\hline \multirow[t]{2}{*}{ Pneumonia } & $79(21.8)$ & With & $72.2 \pm 5.0$ & 0.075 & NS & \\
\hline & & Without & $80.9 \pm 2.3$ & & & \\
\hline \multirow[t]{2}{*}{ Sarcoidosis } & $22(6.1)$ & With & $86.4 \pm 7.3$ & 0.576 & NS & \\
\hline & & Without & $78.5 \pm 2.2$ & & & \\
\hline \multirow[t]{2}{*}{ Inflammatory arthritis } & $34(9.4)$ & With & $76.5 \pm 7.3$ & 0.960 & NS & \\
\hline & & Without & $79.3 \pm 2.2$ & & & \\
\hline \multirow[t]{2}{*}{ Thoracic surgery\# } & $56(15.4)$ & With & $87.5 \pm 4.4$ & 0.036 & NS & \\
\hline & & Without & $77.5 \pm 2.4$ & & & \\
\hline \multirow[t]{2}{*}{ Lung cancer survivor } & $22(5.7)$ & With & $77.3 \pm 8.9$ & 0.081 & NS & \\
\hline & & Without & $79.1 \pm 2.2$ & & & \\
\hline \multirow[t]{2}{*}{ Other } & $25(6.9)$ & With & $64.0 \pm 9.6$ & 0.502 & NS & \\
\hline & & Without & $80.1 \pm 2.2$ & & & \\
\hline
\end{tabular}

Data are presented as $\mathrm{n}(\%)$ or $\% \pm \mathrm{SE}$, unless otherwise stated. TB: tuberculosis; NTM: nontuberculous mycobacteria; COPD: chronic obstructive pulmonary disease; ABPA: allergic bronchopulmonary aspergillosis; NS: nonsignificant. \#: 25 patients had pleural surgery, 23 had resection and seven had other procedures. Additionally, some conditions had a prevalence too small to justify statistical analysis; these were childhood pneumonia $(n=11)$, asbestos-related pleural disease $(n=9)$ and prior subacute invasive aspergillosis $(n=9)$.

Sputum from patients was sent to the microbiology laboratory at the hospital for fungal culture and if culture-positive then the isolate was sent to the NAC Mycology Reference Centre Manchester for identification and susceptibility testing. Samples were usually submitted on multiple occasions for each patient. Positive cultures for Aspergillus species were obtained in 48 patients; Aspergillus fumigatus in 43. Of these, 20 (47\%) were fully susceptible to all azoles tested (itraconazole, voriconazole and posaconazole). Eight (19\%) were pan-azole resistant and the remainder had reduced susceptibility to at least one azole. Other Aspergillus species were isolated: one each of A. niger complex, A. terreus, A. nidulans, A. glaucus (of uncertain significance) and one unspeciated isolate. The 10-year survival of patients with isolates fully susceptible to azoles was $68 \%$, in contrast to $46 \%$ in patients with an isolate with reduced susceptibility to azoles ( $\mathrm{p}=0.143$ by log rank) (figure 2 ).

We did not systematically collect bacterial culture data, primarily because it is likely to be very incomplete. We have assembled information of the bacteria cultured from our patients [29], and 19 (5\%) out of 364 patients attending our service (50\% with CPA) grew Pseudomonas aeruginosa, and slightly fewer grew other rapidly growing bacteria. No attempt was made to analyse any impact on survival of these bacterial infections.

CT scans were available for 320 patients. Pleural disease was seen in 250 (78.1\%) patients, pulmonary cavities in $287(89.7 \%)$ and aspergillomas in 224 (70\%). Bilateral cavities and aspergillomas were seen in $131(40.9 \%)$ and $54(41.6 \%)$ patient CT scans, respectively. The relationship of these different appearances to 2-year survival are shown in table 3. The presence of pleural disease was highly associated with a worse 2 -year survival $(p=0.001)$, as was cavitary disease $(p=0.003)$. Bilateral disease was associated with a worse outcome, and having one or especially bilateral aspergillomas was associated with worse survival (figure 3 ). 39 (12\%) patients had Aspergillus nodules on initial CT imaging; 13 of these were bilateral. Those with Aspergillus nodules did not have significantly different survival to those with other types of CPA (log rank test $\mathrm{p}=0.638$ ). 
FIGURE 2 Survival for the 43 patients with a positive culture that was susceptibility tested ( $p=0.143$ ). 1-, 5- and 10-year survival for fully susceptible patients was $75 \%, 68 \%$ and $68 \%$, respectively; and $87 \%$, $46 \%$ and $46 \%$, respectively for those with resistance or intermediate susceptibility.

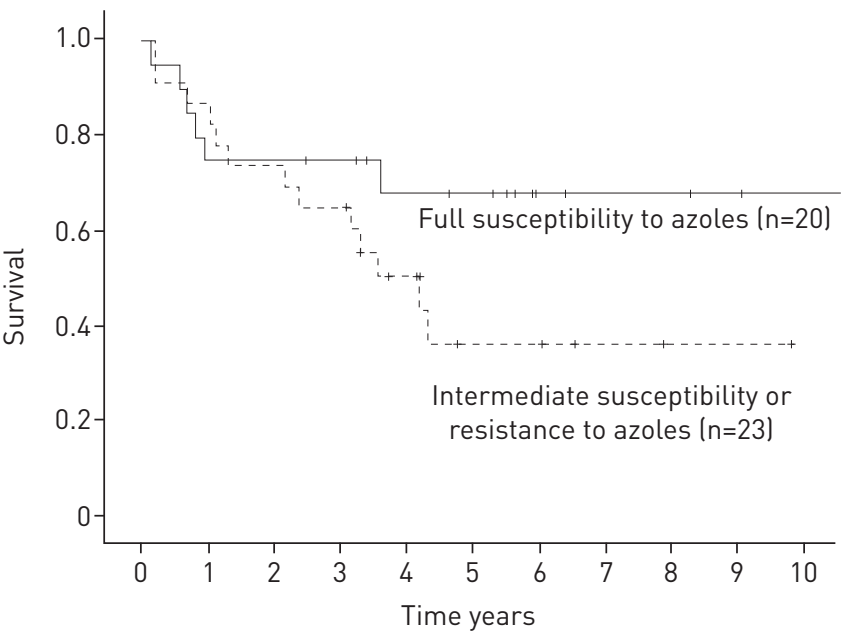

A subsample of 120 patients was reviewed in further detail to collect baseline MRC dyspnoea score $(n=78)$, baseline BMI $(n=88)$ and baseline weight $(n=102)$. Those more breathless with a higher baseline MRC score have shorter survival $(p<0.001)$, as demonstrated in figure 4 . MRC scores 3 and 4 have been grouped for analysis due to ambiguity in the questions used. A unit increase in baseline BMI has a HR of 0.89 (95\% CI $0.81-0.97 ; \mathrm{p}=0.010)$, that is a decrease in mortality risk of $11 \%$. There was a reduction in mortality of $4 \%$ for every $1 \mathrm{~kg}$ increase in weight.

Furthermore, multivariate analysis including age, sex, underlying pulmonary conditions, location and presence of aspergillomas, serum albumin and CRP and SGRQ activity found that previous NTM disease (HR 2.07, 95\% CI 1.22-3.52; $\mathrm{p}=0.007)$, previous COPD (1.57, 1.05-2.36; $\mathrm{p}=0.029)$, age (1.05, 1.03-1.07; $\mathrm{p}<0.001)$, SGRQ activity score $(1.02,1.01-1.03)$ per unit increase, $\mathrm{p}<0.001)$ and albumin $(0.92,0.87-0.96$ per $\left.\mathrm{g} \cdot \mathrm{L}^{-1} ; \mathrm{p}<0.001\right)$, were independent predictors of mortality.

The majority of patients cared for at the NAC who die do so at other centres, and usually after months or years of ill health. Causes of death were available for 40 patients (see online supplementary table S1). CPA was listed either in causal sequence to death or contributing towards death in $27(67.5 \%)$ patients. Three (7.5\%) patients died of conditions unrelated to CPA. 10 (25\%) patients are reported to have died of conditions such as COPD or sarcoidosis, and it is likely that CPA was at least a contributory factor, but was not recorded on the death certificate.

\section{Discussion}

We present a large retrospective cohort analysis of 387 CPA patients whose care was delivered at our specialist centre. We found that poor outcomes in CPA were associated with several objective and subjective

TABLE 3 Radiological features on thoracic computed tomography scans and their association with survival

Patients

Kaplan-Meier analysis/log rank test

2-year survival Comparison of None compared to all three categories unilateral/bilateral

Unilateral compared to bilateral

\begin{tabular}{|c|c|c|c|c|c|}
\hline \multicolumn{6}{|l|}{ Pleural disease } \\
\hline None & $70(21.9)$ & $90.0 \pm 3.6$ & $p=0.003$ & $p=0.001$ & \multirow{3}{*}{$\mathrm{p}=0.851$} \\
\hline Unilateral & $70(21.9)$ & $75.7 \pm 5.1$ & & & \\
\hline Bilateral & $180(56.3)$ & $77.2 \pm 3.1$ & & & \\
\hline None (nodular/pleural disease only) & $33(10.3)$ & $90.9 \pm 5.0$ & $p=0.001$ & $p=0.003$ & \multirow{3}{*}{$p=0.018$} \\
\hline Unilateral & $156(48.8)$ & $83.3 \pm 3.0$ & & & \\
\hline Bilateral & $131(40.9)$ & $72.5 \pm 3.9$ & & & \\
\hline Unilateral & $170(53.1)$ & $80.6 \pm 3.0$ & & & \multirow[t]{2}{*}{$p=0.005$} \\
\hline Bilateral & $54(16.9)$ & $64.8 \pm 6.5$ & & & \\
\hline
\end{tabular}

Data are presented as $n(\%)$ or $\% \pm S E$, unless otherwise stated. $n=320$. 
FIGURE 3 Survival stratified by presence of one or more aspergillomas $(n=340) .1-, 5-$ and 10 -year survival for those with no aspergilloma $88 \%, 71 \%$ and $66 \%$, respectively; $88 \%, 63 \%$ and $49 \%$, respectively for those with unilateral aspergilloma; and $79 \%, 49 \%$ and $18 \%$, respectively for those with bilateral aspergillomas. $p=0.001$.

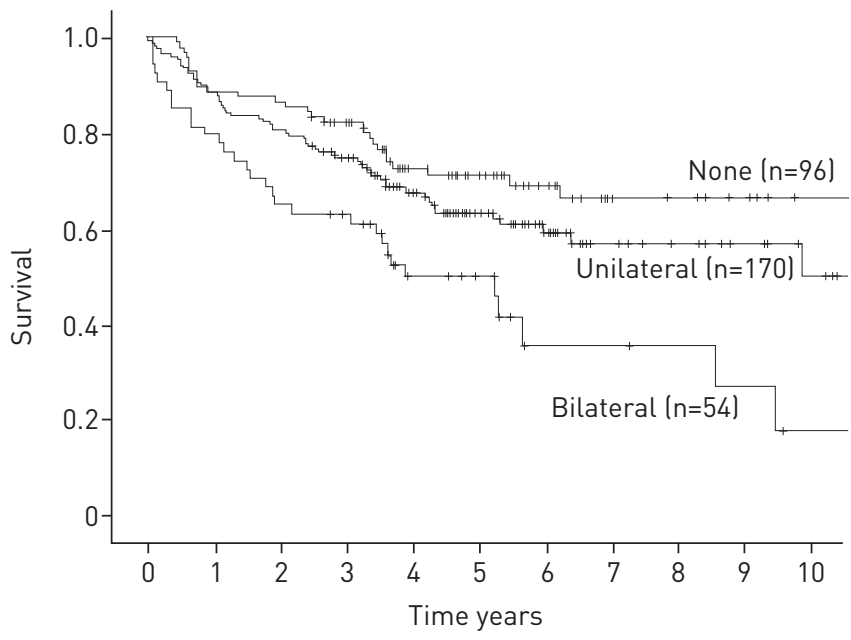

variables. NTM infections, prior COPD, pleural involvement, bilateral cavitary disease or aspergillomas, low body mass and low albumin. Moreover, lower activity score and higher dyspnoea score identified patients with probable worse prognosis. It is likely that azole resistance is associated with a worse outcome, but this did not reach statistical significance.

The 1-, 5- and 10-year survival rates in our 387 patients of $86 \%, 62 \%$ and $47 \%$, respectively, contrasts with other contemporary series from Japan $(n=42)$ and South Korea $(n=43)$ of $63-74 \%, 15-50 \%$ and $26 \%$, respectively $[14,15]$. However, a recent Japanese study with $194 \mathrm{CPA}$ patients reported a closer figure to our finding with cumulative survival rates of $49 \%$ and $34 \%$ at 5 and 10 years, respectively [17]. The underlying disease distribution and baseline age in these series differed (table 1), mostly without sufficient detail to comment on relative risks.

Once CCPA is established, an aspergilloma may form. The stages of formation of a fungal ball on CT scan have been well illustrated by ROBERTs et al. [30], and a radiologically visible aspergilloma represents an advanced stage of infection. Therefore, it is not surprising that bilateral aspergillomas carry a worse prognosis than either no aspergilloma or a unilateral aspergilloma (figure 3). Both the presence of pleural disease (unilateral or bilateral) or cavitary disease (unilateral or, especially, bilateral) also confer a poorer outcome. In contrast, nodules and intraluminal cavities, without pleural involvement, confer a better outcome. The reason for these associations with earlier death is not apparent. However, in addition to coexisting structural tissue damage, several inflammatory, immunological and genetic features are associated with CPA development and progression. Increased CRP has been associated with increased mortality risk in CPA [17]. Low mannose-binding lectin is associated with worse breathlessness in CPA [31, 32], not risk of disease.

Previous infection by NTM was shown to be an independent predictor of mortality. This may represent the level of underlying damage caused by the infection. Three studies have examined the relationship between

FIGURE 4 Severity of breathlessness and outcome as determined by the Medical Research Council (MRC) dyspnoea score in a subset of patients ( $n=78 ; p<0.001)$. 1 - and 5 -year survival for those with an MRC score of 1: $100 \%$ and $89 \%$, respectively; $96 \%$ and $79 \%$, respectively for those with a score of $2 ; 91 \%$ and $47 \%$, respectively for those with a score of 3 or 4 ; and $46 \%$ and $21 \%$, respectively for those with a score of 5 .

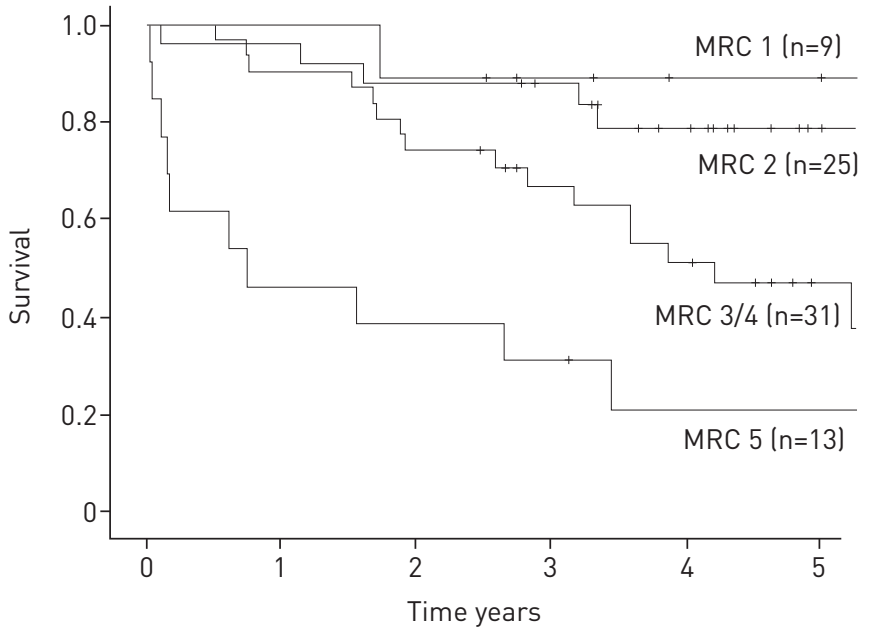


NTM and CPA, showing that in patients with NTM, CPA is an independent predictor of mortality [33, 34]. Furthermore, TAKEDA et al. [19] recently found that the nontreatment of CPA in NTM co-infected patients led to a higher mortality, suggesting that the driver for death was the CPA, not the NTM infection. Another group have shown there is a risk of developing NTM in cavities caused by CPA [35].

Clinically, these findings underscore the prognostic importance of early referral to specialist centres to establish diagnosis, commence treatment and prevent further lung tissue destruction and life-threatening manifestations such as haemoptysis. Indeed, delayed or inadequate antifungal therapy is usually associated with progression, whereas sustained clinical response is usually associated with long-term antifungal therapy. Second, early referral can assist in timely identification of patients who progress rapidly and may need immunotherapy (usually replacement $\gamma$-interferon) or challenging surgery, prevention of antifungal resistance and alternative antifungal options for those who cannot take or fail azole therapy. Third, given the estimated 3 million patients with CPA worldwide [2], additional antifungal agents and strategies to prevent lung fibrosis and/or destruction are necessary.

$\mathrm{BMI}$ is a functional marker of poor prognosis in CPA, and our finding confirms the results of previous smaller studies $[15,17]$. We observed that a unit increase in baseline BMI was associated with an $11 \%$ decrease in mortality risk. Moreover, we found low weight to be a useful indicator of poor prognosis, as in other chronic progressive respiratory illnesses, e.g. COPD $[36,37]$, possibly attributable to chronic systemic inflammation [38, 39]. Elevated inflammatory biomarkers are associated with poor prognosis in CPA [17], COPD [39] and lung fibrosis [40], and could be directly involved in lung tissue destruction and body mass depletion [41] in CPA.

Older age was associated with poor outcomes in CPA and other respiratory illnesses [17, 42]. We also found albumin to be a useful prognostic marker which remained statistically significant in multivariate analysis, as in other respiratory conditions [43].

Moreover, we found that breathlessness as measured by the MRC dyspnoea score was a predictor of poor outcome. This replicates our recent finding from longitudinal analysis (quarterly over a year) where the MRC dyspnoea score was an independent prognostic factor [9]; this is also seen in COPD [44]. MRC dyspnoea scores have only been collected in our centre since late 2009, hence the shorter follow-up time, and yet those few without breathlessness (MRC score of 1 ) all survived to $\geqslant 3$ years compared to only $26 \%$ of those with an MRC score of 5 (figure 4). Although the MRC dyspnoea scale is an old and simple measure, it has considerable clinical value in assessing respiratory diseases prognosis $[9,44]$.

Lower activity domain scores of the SGRQ were a stronger predictor of mortality in a model consisting of all the SGRQ outputs. Prior studies showed that the SGRQ activity domain correlated better than the total SGRQ score with key respiratory measurements such as forced expiratory volume in $1 \mathrm{~s}$, arterial oxygen tension and exercise capacity (shuttle distance) [45]. This finding is not surprising, since the SGRQ is a respiratory-specific and sensitive tool in identifying patients at risk of mortality [11] and detects response to antifungal treatment [9]. Regular physical activity associates with reduced hospital readmission and mortality risk, as in COPD [10], and promoting physical activity is a promising step in lowering rehospitalisation [46], which needs addressing in CPA patients.

The NAC sees patients from all over the UK, with higher referral rates from the northwest of England and more complex patients referred from longer distances. Both short-term and long-term health benefits with antifungal therapy (either improvement or prevention of progression of disease) are obvious for some patients [7-9]. Unfortunately, antifungal therapy is often curtailed by numerous adverse events [9, 47]. Triazole antifungal resistance is a relatively frequent problem [48-50], interrupting azole therapy, probably with a worse outcome in CPA as seen here. Intermittent or occasionally long-term i.v. liposomal amphotericin B or micafungin provide some short-term benefits for some patients unable to take oral therapy or with pan-azole resistance.

Although we presented key prognostic factors that would assist in identifying patients at risk of poor prognosis, our study has limitations. We could not achieve a full dataset for all our patients, a common limitation in retrospective analysis. Substantial effort was made to collect reliable data, and develop the largest dataset so far on this currently incurable destructive lung disease. Second, azole resistance may be correlated with poor outcomes, and this may need analyses of a bigger sample size. Finally, we do not have sufficient data on causes of death in our CPA cohort, with death certificates being incomplete and often inaccurate. However, this analysis has underscored the importance of careful recording of mortality causes in CPA.

In conclusion, more than half of our CPA patients had died by the tenth anniversary of their referral. Several pulmonary and extrapulmonary factors associated with high mortality risk are identified: NTM infection, COPD, pleural involvement, cavitary disease, presence of an aspergilloma, shortness of breath, low physical activity and low body mass. Early diagnosis, referral and improved treatments are required. 


\section{Acknowledgements}

We are indebted to Edmund Jessop and the national Highly Specialised Services Commissioning team in the National Health Service for their consistent support of the National Aspergillosis Centre (NAC). The multiple contributions to care by the physicians, nurses, physiotherapists and the Mycology Reference Centre Manchester (MRCM) staff are all gratefully acknowledged. The commissioning of the NAC would not have been possible without long-term support of the Aspergillus Website and the MRCM from the Fungal Infection Trust.

The authors' contributions are as follows. David Lowes participated in the study design and data collection and analysis, and manuscript writing, drafting and reviewing. Khaled Al-Shair participated in data analysis, manuscript writing, drafting, editing and reviewing. Pippa J. Newton participated in data analysis and manuscript reviewing. Julie Morris participated in data analysis and manuscript reviewing. Chris Harris participated in data collection and analysis and manuscript reviewing. Riina Rautemaa-Richardson participated in data analysis and manuscript writing, reviewing and editing. David W. Denning participated in study design, data analysis and manuscript writing, editing and reviewing. All authors read and approved the manuscript.

\section{References}

1 Smith NL, Denning DW. Underlying conditions in chronic pulmonary aspergillosis including simple aspergilloma. Eur Respir J 2011; 37: 865-872.

2 Brown GD, Denning DW, Gow NAR, et al. Hidden killers: human fungal infections. Sci Transl Med 2012; 4: 165 rv13.

3 Denning DW, Riniotis K, Dobrashian R, et al. Chronic cavitary and fibrosing pulmonary and pleural aspergillosis: case series, proposed nomenclature change, and review. Clin Infect Dis 2003; 37: Suppl. 3, S265-S280.

4 Muniappan A, Tapias LF, Butala P, et al. Surgical therapy of pulmonary aspergillomas: a 30-year North American experience. Ann Thorac Surg 2014; 97: 432-438.

5 Farid S, Mohamed S, Devbhandari M, et al. Results of surgery for chronic pulmonary aspergillosis, optimal antifungal therapy and proposed high risk factors for recurrence - a National Centre's experience. J Cardiothorac Surg 2013; 8: 180 .

6 Reddy PA, Christianson CS, Brasher CA, et al. Comparison of treated and untreated pulmonary aspergilloma. Am Rev Respir Dis 1970; 101: 928-934.

7 Felton TW, Baxter C, Moore CB, et al. Efficacy and safety of posaconazole for chronic pulmonary aspergillosis. Clin Infect Dis 2010; 51: 1383-1391.

8 Cadranel J, Philippe B, Hennequin C, et al. Voriconazole for chronic pulmonary aspergillosis: a prospective multicenter trial. Eur J Clin Microbiol Infect Dis 2012; 31: 3231-3239.

9 Al-Shair K, Atherton GT, Harris C, et al. Long-term antifungal treatment improves health status in patients with chronic pulmonary aspergillosis: a longitudinal analysis. Clin Infect Dis 2013; 57: 828-835.

10 Garcia-Aymerich J, Lange P, Benet M, et al. Regular physical activity reduces hospital admission and mortality in chronic obstructive pulmonary disease: a population based cohort study. Thorax 2006; 61: 772-778.

11 Jones PW. Health status and the spiral of decline. COPD 2009; 6: 59-63.

12 Jewkes J, Kay PH, Paneth M, et al. Pulmonary aspergilloma: analysis of prognosis in relation to haemoptysis and survey of treatment. Thorax 1983; 38: 572-578.

13 Tomlinson JR, Sahn SA. Aspergilloma in sarcoid and tuberculosis. Chest 1987; 92: 505-508.

14 Nam HS, Jeon K, Um SW, et al. Clinical characteristics and treatment outcomes of chronic necrotizing pulmonary aspergillosis: a review of 43 cases. Int J Infect Dis 2010; 14: e479-e482.

15 Ohba H, Miwa S, Shirai M, et al. Clinical characteristics and prognosis of chronic pulmonary aspergillosis. Respir Med 2012; 106: 724-729.

16 Jhun BW, Jeon K, Eom JS, et al. Clinical characteristics and treatment outcomes of chronic pulmonary aspergillosis. Med Mycol 2013; 51: 811-817.

17 Nakamoto K, Takayanagi N, Kanauchi T, et al. Prognostic factors in 194 patients with chronic necrotizing pulmonary aspergillosis. Intern Med 2013; 52: 727-734.

18 Camara B, Reymond E, Saint-Raymond C, et al. Characteristics and outcomes of chronic pulmonary aspergillosis: a retrospective analysis of a tertiary hospital registry. Clin Respir J 2015; 9: 65-73.

19 Takeda K, Imamura Y, Takazono T, et al. The risk factors for developing of chronic pulmonary aspergillosis in nontuberculous mycobacteria patients and clinical characteristics and outcomes in chronic pulmonary aspergillosis patients coinfected with nontuberculous mycobacteria. Med Mycol 2016; 54: 120-127.

20 Chan JF, Lau SK, Wong SC, et al. A 10-year study reveals clinical and laboratory evidence for the 'semi-invasive' properties of chronic pulmonary aspergillosis. Emerg Microbes Infect 2016; 5: e37.

21 Denning DW, Cadranel J, Beigelman-Aubry C, et al. Chronic pulmonary aspergillosis: rationale and clinical guidelines for diagnosis and management. Eur Respir J 2016; 47: 45-68.

22 Page ID, Richardson MD, Denning DW. Comparison of six Aspergillus-specific IgG assays for the diagnosis of chronic pulmonary aspergillosis (CPA). J Infect 2016; 72: 240-249.

23 Bestall JC, Paul EA, Garrod R, et al. Usefulness of the Medical Research Council (MRC) dyspnoea scale as a measure of disability in patients with chronic obstructive pulmonary disease. Thorax 1999; 54: 581-586.

24 Fletcher CM. Standardised questionnaire on respiratory symptoms: a statement prepared and approved by the MRC Committee on the Aetiology of Chronic Bronchitis (MRC breathlessness score). BMJ 1960; 2; 1665 .

25 Jones PW, Quirk FH, Baveystock CM, et al. A self-complete measure of health status for chronic airflow limitation. The St. George's Respiratory Questionnaire. Am Rev Respir Dis 1992; 145: 1321-1327.

26 Jones PW. St. George's Respiratory Questionnaire: MCID. COPD 2005; 2: 75-79.

27 Al-shair K, Atherton GT, Kennedy D, et al. Validity and reliability of the St. George's Respiratory Questionnaire in assessing health status in patients with chronic pulmonary aspergillosis. Chest 2013; 144: 623-631.

28 Sambatakou H, Dupont B, Lode $\mathrm{H}$, et al. Voriconazole treatment for subacute invasive and chronic pulmonary aspergillosis. Am J Med 2006; 119: 527.e17-24.

29 Langridge P, Sheehan R, Denning DW. Microbial yield from physiotherapy assisted sputum production in respiratory outpatients. BMC Pulm Med 2016; 16: 23 . 

Radiology 1987; 165: 123-128. for chronic necrotizing pulmonary aspergillosis. J Infect Dis 2001; 184: 653-656.

32 Harrison E, Singh A, Morris J, et al. Mannose-binding lectin genotype and serum levels in patients with chronic and allergic pulmonary aspergillosis. Int J Immunogenet 2012; 39: 224-232.

33 Ishikawa S, Yano S, Kadowaki T, et al. [Clinical analysis of non-tuberculous mycobacteriosis cases complicated with pulmonary aspergillosis]. Kekkaku 2011; 86: 781-785.

34 Zoumot Z, Boutou AK, Gill SS, et al. Mycobacterium avium complex infection in non-cystic fibrosis bronchiectasis. Respirology 2014; 19: 714-722.

35 Fujiuchi S, Sakunami M, Yamamoto Y, et al. [Analysis of chronic necrotizing pulmonary aspergillosis (CNPA) cases complicated with non-tuberculous mycobacteriosis (NTM)]. Kekkaku 2008; 83: 573-575.

36 Vestbo J, Prescott E, Almdal T, et al. Body mass, fat-free body mass, and prognosis in patients with chronic obstructive pulmonary disease from a random population sample: findings from the Copenhagen City Heart Study. Am J Respir Crit Care Med 2006; 173: 79-83.

37 Schols A, Slangen J, Volovics L, et al. Weight loss is a reversible factor in the prognosis of chronic obstructive pulmonary disease. Am J Respir Crit Care Med. 1998; 157: 1791-1797.

38 Di Francia M, Barbier D, Mege JL, et al. Tumor necrosis factor-alpha levels and weight loss in chronic obstructive pulmonary disease. Am J Respir Crit Care Med 1994; 150: 1453-1455.

39 Eid AA, Ionescu AA, Nixon LS, et al. Inflammatory response and body composition in chronic obstructive pulmonary disease. Am J Respir Crit Care Med 2001; 164: 1414-1418.

40 Richards TJ, Kaminski N, Baribaud F, et al. Peripheral blood proteins predict mortality in idiopathic pulmonary fibrosis. Am J Respir Crit Care Med 2012; 185: 67-76.

41 Fabbri LM, Rabe KF. From COPD to chronic systemic inflammatory syndrome? Lancet 2007; 370: 797-799.

42 Thannickal VJ, Murthy M, Balch WE, et al. Blue journal conference. Aging and susceptibility to lung disease. Am J Respir Crit Care Med 2015; 191: 261-269.

43 Komiya K, Oka H, Ohama M, et al. Evaluation of prognostic differences in elderly patients with pneumonia treated by between pulmonologists and non-pulmonologists: a propensity score analysis. Clin Respir J 2016; 10: $462-468$.

44 Nishimura K, Izumi T, Tsukino M, et al. Dyspnea is a better predictor of 5-year survival than airway obstruction in patients with COPD. Chest 2002; 121: 1434-1440.

45 Wilson CB, Jones PW, O'Leary CJ, et al. Validation of the St. George's Respiratory Questionnaire in bronchiectasis. Am J Respir Crit Care Med 1997; 156: 536-541.

46 Nguyen HQ, Chu L, Amy Liu IL, et al. Associations between physical activity and 30-day readmission risk in chronic obstructive pulmonary disease. Ann Am Thorac Soc 2014; 11: 695-705.

47 Baxter CG, Marshall A, Roberts M, et al. Peripheral neuropathy in patients on long-term triazole antifungal therapy. J Antimicrob Chemother 2011; 66: 2136-2139.

48 Bowyer P, Moore CB, Rautemaa R, et al. Azole antifungal resistance today: focus on Aspergillus. Curr Infect Dis Rep 2011; 13: 485-491.

49 Denning DW, Park S, Lass-Florl C, et al. High-frequency triazole resistance found in nonculturable Aspergillus fumigatus from lungs of patients with chronic fungal disease. Clin Infect Dis 2011; 52: 1123-1129.

50 Howard SJ, Cerar D, Anderson MJ, et al. Frequency and evolution of azole resistance in Aspergillus fumigatus associated with treatment failure. Emerging Infect Dis 2009; 15: 1068-1076. 